\title{
Effect of the solution composition and the applied potential on the kinetics of roughness relaxation at gold electrodes in slightly acid electrolytes
}

\author{
M.P. García and M.M. Gómez \\ Departamento de Química-Física Aplicada, C-II, Facultad de Ciencias, \\ Universidad Autónoma de Madrid, 28049 Madrid, (Spain)
}

\author{
R.C. Salvarezza and A.J. Arvia * \\ Instituto de Investigaciones Fisicoquímicas Teóricas y Aplicadas (INIFTA), Casilla de Correo 16, \\ Sucursal 4, 1900 La Plata (Argentina)
}

(Received 26 June 1992; in revised form 7 September 1992)

\begin{abstract}
The roughness relaxation of thin columnar Au electrodeposits at constant potential and $25^{\circ} \mathrm{C}$ in 0.05 $\mathrm{M} \mathrm{NaF}, 0.05 \mathrm{M} \mathrm{KCl}$ and $0.05 \mathrm{M} \mathrm{K}_{2} \mathrm{SO}_{4}$ has been studied. These measurements were taken in the -0.6 to $0.8 \mathrm{~V}$ (vs $\mathrm{Hg} / \mathrm{Hg}_{2} \mathrm{SO}_{4}$ reference electrode) potential range. The kinetic data were obtained from the roughness factor decay over $5 \times 10^{4} \mathrm{~s}$. The value of the surface diffusion coefficient $D_{\mathrm{s}}$ of $A u$ atoms was derived from the roughness decay law at constant potential and $\mathrm{pH}$. At any potential, the value of $D_{\mathrm{s}}$ increases in the order $\mathrm{NaF}<\mathrm{K}_{2} \mathrm{SO}_{4}<\mathrm{KCl}$. This sequence correlates with the specific adsorption of anions on $\mathrm{Au}$. In $\mathrm{K}_{2} \mathrm{SO}_{4}$ and $\mathrm{NaF}$ solutions, as the electroformation of $\mathrm{AuOH}$ species takes place, the effect of $\mathrm{SO}_{4}^{2-}$ and $\mathrm{F}^{-}$ions is no longer observed. In contrast, in $0.05 \mathrm{M} \mathrm{KCl}$ solution, the value of $D_{\mathrm{s}}$ increases steadily as the applied potential is increased positively.
\end{abstract}

\section{INTRODUCTION}

Surface roughness relaxation phenomena on metals in the range $273-325 \mathrm{~K}$ offer the possibility of deriving quantitative information about the mobility of surface atoms either in vacuo or at metal-aqueous solution interfaces [1-3].

\footnotetext{
To whom correspondence should be addressed.
} 
Knowledge of these phenomena becomes of particular interest, for instance, for understanding those surface processes which determine the stability and duration of large metal area catalysts and the mechanisms of metallic corrosion processes, such as stress corrosion cracking.

Recent investigations on electrodispersed metal electrodes, based on scanning tunnelling microscopy (STM) combined with scanning electron microscopy (SEM), have shown that these electrodes, which can be described as columnar-like structures, exhibit roughness relaxation, implying the radial growth of columns at a practically constant height [2]. The kinetics of this process can be followed through the time dependence of the surface roughness factor $R$, followed by electroadsorption measurements, employing appropriate molecules or atoms as references. The roughness relaxation of electrodispersed metal electrodes obeys the rate equation [2]

$R^{-1}=(3 / \pi h)\left(B t+r_{0}^{4}\right)^{1 / 4}$

where $B=\left(2 \gamma a^{4} D_{\mathrm{s}} / k T\right), \gamma$ is the surface tension (surface Gibbs energy) of the metal, $a$ is the corresponding lattice parameter, $D_{\mathrm{s}}$ is the surface diffusion coefficient of metal atoms at temperature $T, k$ is Boltzmann's constant, $r$ is the instantaneous average radius of columns and $r_{0}$ is the value of $r$ for $t=0$. Equation (1) for $t \rightarrow \infty$ and $r \gg r_{0}$ becomes

$R^{-1}=(3 / \pi h) B^{1 / 4} t^{1 / 4}$

and, for $t \rightarrow 0$, it gives

$R^{-1}=3 r_{0} / \pi h$

Thus, from the slope of the $R^{-1}$ vs. $t^{1 / 4}$ linear plots (eqn. (2)), $D_{s}$ can be evaluated. This method has allowed us to measure, for the first time, values of $D_{\mathrm{s}}$ and $E_{\mathrm{s}}$, the activation energy for surface diffusion, for polycrystalline $\mathrm{Au}$ and $\mathrm{Pt}$ in aqueous, acid electrolytes [2]. For Au at $298 \mathrm{~K}$, the values $D_{\mathrm{s}} \cong 1 \times 10^{-14} \mathrm{~cm}^{2} \mathrm{~s}^{-1}$ and $E_{\mathrm{s}} \cong 58 \mathrm{~kJ} \mathrm{~mol}^{-1}$ were reported [2]. These numbers are close to $D_{\mathrm{s}}=2 \times 10^{-15}$ $\mathrm{cm}^{2} \mathrm{~s}^{-1}$ and $E_{\mathrm{s}}=50 \mathrm{~kJ} \mathrm{~mol}^{-1}$, which very recently were reported for the surface mobility of $\mathrm{Au}(111)$ in $\mathrm{HClO}_{4}$ at room temperature through pit radii measurements by in situ STM imaging [4]. The reasonable coincidence of these numbers supports the validity of the present method of estimating $D_{\mathrm{s}}$ and $E_{\mathrm{s}}$.

Au is widely recognized as a suitable metal for surface diffusion studies, owing to its relatively high surface atom mobility at room temperature [5]. Recently, roughness relaxation measurements of electrodispersed $\mathrm{Au}$ electrodes, made in the presence of either $\mathrm{Cl}^{-}$or $\mathrm{SO}_{4}^{2-}$ ions under open circuit conditions [3], demonstrated that $\mathrm{Cl}^{-}$ion adsorption increases markedly the value of $D_{\mathrm{s}}$, whereas $\mathrm{SO}_{4}^{2-}$ ion adsorption produces only a slight increase in $D_{s}[3]$ with respect to those values reported for $\mathrm{Au}$ in vacuo or in air [2]. However, the comparison of $D_{\mathrm{s}}$ values determined in different electrolytes with an open circuit potential becomes rather uncertain, because the open circuit potential values change with the electrolyte composition. It is clear that, if anion adsorption affects $D_{\mathrm{s}}$, and with anion 
adsorption changing with the applied potential, according to the adsorption isotherm, a marked effect of the applied potential on $D_{\mathrm{s}}$ should be expected. Thus, it is important to study the roughness relaxation of these electrodes under potentiostatic conditions. Despite the fact that $\mathrm{Au}$ also exhibits a potentialdependent surface reconstruction for well-defined, single-crystal faces [6-8], this reconstruction involves small changes in $R$ (of the order of 2-1), which are much smaller than the changes in $R$ (of the order of 100-10) resulting from particle growth phenomena [2].

The present paper is devoted to investigating the roughness relaxation of electrodispersed $\mathrm{Au}$ electrodes in $0.05 \mathrm{M} \mathrm{NaF}, 0.05 \mathrm{M} \mathrm{KCl}$ and $0.05 \mathrm{M} \mathrm{K}_{2} \mathrm{SO}_{4}$ at pH 5.0 under potentiostatic conditions, covering a wide potential range in the absence of interfering faradaic processes.

\section{EXPERIMENTAL}

The electrochemical runs were performed with a conventional cell, involving an electrodispersed $\mathrm{Au}$ working electrode (EDAuE), a large-area Au counterelectrode, and an $\mathrm{Hg} / \mathrm{Hg}_{2} \mathrm{SO}_{4} / \mathrm{K}_{2} \mathrm{SO}_{4}$ (sat.) (MSE) reference electrode. All the potential values given in the text refer to the MSE scale. The entire experiments were performed under purified $\mathrm{N}_{2}$ at $298 \mathrm{~K}$.

The in situ preparation of EDAuEs has been described extensively elsewhere $[9,10]$. Briefly, a polycrystalline Au wire electrode immersed in $0.5 \mathrm{M} \mathrm{H}_{2} \mathrm{SO}_{4}$ at room temperature was anodized at $2.0 \mathrm{~V}$ for a preset time to accumulate a certain amount of hydrous Au oxide. The amount of hydrous Au oxide can be controlled through the duration of the anodization time. Subsequently, the hydrous $\mathrm{Au}$ oxide layer was electroreduced by applying a potential sweep from 1.0 to $-0.6 \mathrm{~V}$ at 0.1 $\mathrm{V} \mathrm{s}^{-1}$. The resulting EDAuEs exhibited average thickness values ranging between $4 \times 10^{-6}$ and $3 \times 10^{-4} \mathrm{~cm}$, depending on the amount of $\mathrm{Au}$ oxide accumulated on the Au substrate.

The roughness relaxation of the EDAuEs immersed in the deaerated working solution under a constant applied potential $E_{\mathrm{g}}$ was followed by stepwise evaluation of the electrode roughness factor $R$ in the range $-0.6 \leq E_{\mathrm{g}} \leq 0.8 \mathrm{~V}$, using the following aqueous solutions: $0.05 \mathrm{M} \mathrm{NaF}, 0.05 \mathrm{M} \mathrm{K}_{2} \mathrm{SO}_{4}$ and $0.05 \mathrm{M} \mathrm{KCl}$ at pH 5 . The value of $R$ was determined voltammetrically from the ratio of the $\mathrm{O}$ adatom monolayer electrodesorption charge from the EDAuE at a given time to the $O$ adatom monolayer electrodesorption charge from the untreated $\mathrm{Au}$ electrode. For this purpose, voltammograms were carried out in $1 \mathrm{M} \mathrm{H}_{2} \mathrm{SO}_{4}$ at $0.1 \mathrm{~V} \mathrm{~s}^{-1}$ between -0.6 and $1.1 \mathrm{~V}$. After each determination of $R$, which lasted less than $3 \mathrm{~min}$, the EDAuE was returned into the cell containing the working solution to continue the roughness relaxation. Similar voltammograms recorded between -0.6 and $1.1 \mathrm{~V}$ on smooth Au wires or stabilized $(100 \mathrm{~h})$ EDAuEs show no changes in $R$. Thus, the observed decay in $R$ cannot be assigned to the oxide formation and removal produced during the voltammetric measurements to estimate $R$. This fact agrees with in situ STM results for $\mathrm{Au}(111)$ in $\mathrm{HClO}_{4}$, showing that cycles to potentials, at 


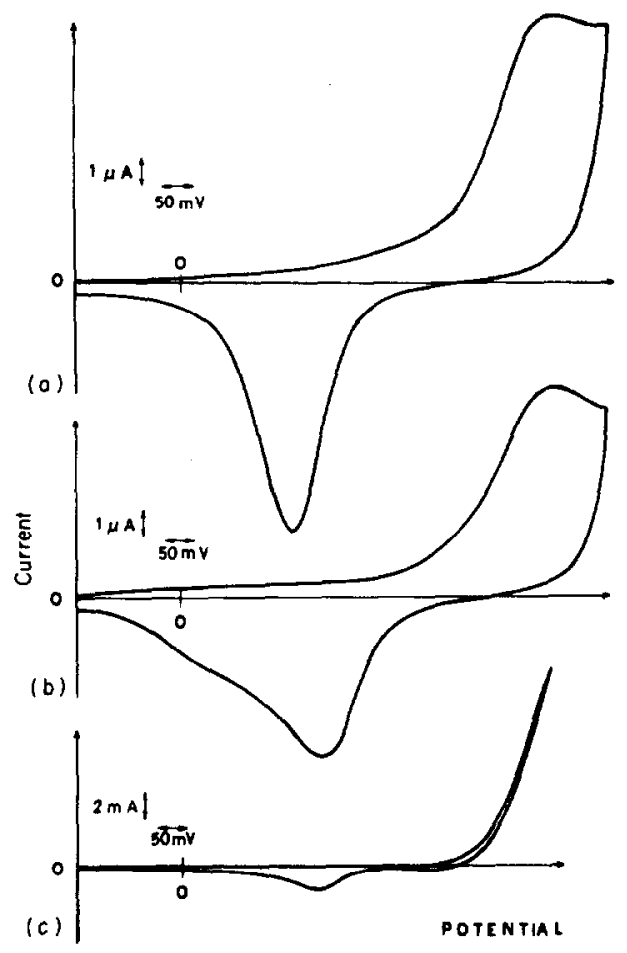

Fig. 1. Voltammograms for polycrystalline Au electrodes $(R=1)$ recorded at $0.01 \mathrm{~V} \mathrm{~s}^{-1}$ in (a) $0.05 \mathrm{M}$ $\mathrm{NaF}$, (b) $0.05 \mathrm{M} \mathrm{K}_{2} \mathrm{SO}_{4}$ and (c) $0.05 \mathrm{M} \mathrm{KCl}$ at $25^{\circ} \mathrm{C}$.

which no more than an oxide monolayer is formed, do not result in changes in the surface roughness [11].

\section{RESULTS AND DISCUSSION}

The voltammograms of the Au electrodes $(R \approx 1)$ recorded at $0.01 \mathrm{~V} \mathrm{~s}^{-1}$ in slightly acid (pH 5.00) $0.05 \mathrm{M} \mathrm{NaF}, 0.05 \mathrm{M} \mathrm{K}_{2} \mathrm{SO}_{4}$ and $0.05 \mathrm{M} \mathrm{KCl}$ are shown in Fig. 1. In $0.05 \mathrm{M} \mathrm{NaF}$ and $0.05 \mathrm{M} \mathrm{K}_{2} \mathrm{SO}_{4}$, the voltammograms exhibit the broad anodic and cathodic current peaks related to the electroformation and the electroreduction of $\mathrm{Au}$ oxide layers. In contrast, in $\mathrm{KCl}$ aqueous solutions, a remarkable increase in the anodic current occurs at potentials more positive than $0.37 \mathrm{~V}$, owing to the electrodissolution of $\mathrm{Au}$ in the solution. Previous results [12] on the electrochemical behaviour of $\mathrm{Au}$ in solutions containing $\mathrm{Cl}^{-}$ions show that $\mathrm{Au}$ dissolves anodically at potentials more positive than $0.3 \mathrm{~V}$. However, the extrapolated anodic current, even at $0.4 \mathrm{~V}$, is smaller than $10^{-7} \mathrm{~A} \mathrm{~cm}^{-2}$ [13]. Accordingly, $0.4 \mathrm{~V}$ was fixed as the upper potential limit for the roughness relaxation in $0.05 \mathrm{M}$ $\mathrm{KCl}$. No difference in the voltammograms, except for the increase in the voltam- 


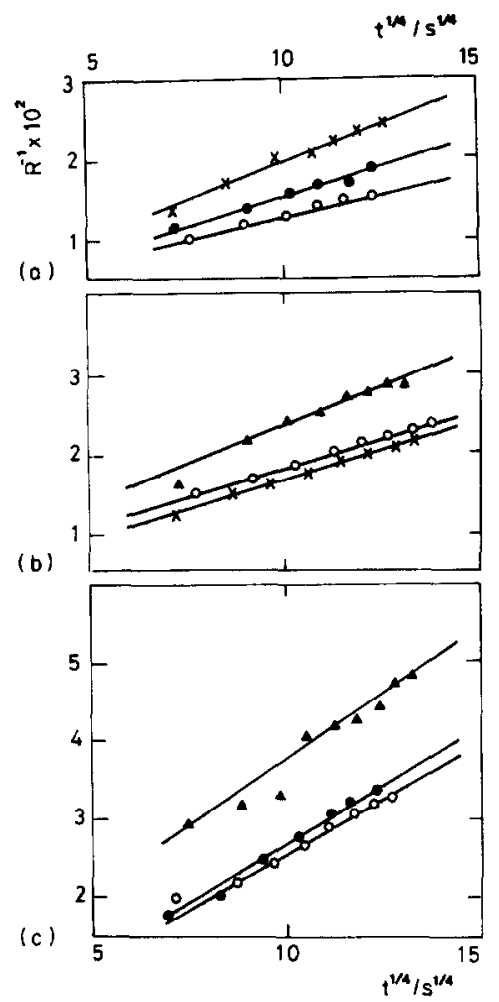

Fig. 2. Typical $1 / R$ vs. $t^{1 / 4}$ plots at different $E_{\mathrm{g}}$ values: (a) $0.05 \mathrm{M} \mathrm{K}_{2} \mathrm{SO}_{4}, E_{\mathrm{g}}=-0.6 \mathrm{~V}(0),-0.45 \mathrm{~V}$ $(\bullet), 0.4 \mathrm{~V}(\times)$; (b) $0.05 \mathrm{M} \mathrm{NaF}, E_{\mathrm{g}}=0.4 \mathrm{~V}(\times),-0.6 \mathrm{~V}(0), 0.2 \mathrm{~V}(\Delta)$; (c) $0.05 \mathrm{M} \mathrm{KCl}, E_{\mathrm{g}}=-0.6 \mathrm{~V}$ $(\mathrm{O}),-0.45 \mathrm{~V}(\bullet), 0.2 \mathrm{~V}(\Delta)$ at $25^{\circ} \mathrm{C}$.

metric charge, could be observed when the $R$ values of the EDAuEs were increased from 1 to 100 .

Typical $R$ vs. $t^{-1 / 4}$ plots obtained for EDAuEs in $0.05 \mathrm{M} \mathrm{NaF}, 0.05 \mathrm{M} \mathrm{KCl}$ and $0.05 \mathrm{M} \mathrm{K}_{2} \mathrm{SO}_{4}$ solutions at different $E_{\mathrm{g}}$ values are depicted in Fig. 2. By using the value of $R^{-1}$ for $t=0$ and eqn. (3), $r_{0}$ is determined to be close to $5 \times 10^{-7} \mathrm{~cm}$. Otherwise, from the slopes of the straight lines, the $D_{\mathrm{s}}$ values at different $E_{\mathrm{g}}$. values can be calculated through eqn. (2), taking $a=4.07 \times 10^{-8} \mathrm{~cm}, r_{0}=5 \times 10^{-7}$ $\mathrm{cm}$, values of $h$ obtained from eqn. (3) and values of $\gamma$ derived from the electrocapillary curves. To evaluate the effect of the change of $\gamma(\Delta \gamma)$ on $D_{\mathrm{s}}$, the $\gamma$ vs. $E$ plot was determined for each electrolyte solution (Fig. 3). The electrocapillary curves were obtained following the method of Grahame et al. [14], using the following integration constants; the metal charge density, $\sigma^{\mathrm{m}}=14 \mu \mathrm{C} \mathrm{cm}^{-2}$ at $E=-1.1 \mathrm{~V}$ and $\gamma=900 \mathrm{erg} \mathrm{cm}{ }^{-2}\left(1 \mathrm{erg} \equiv 10^{-7} \mathrm{~J}\right)$ at $E=E_{\mathrm{pcz}}$, the potential of zero charge.

The values $\Delta \gamma, D_{\mathrm{s}}$ and $D_{\mathrm{sc}}$, the corrected values of $D_{\mathrm{s}}$, at different potentials for the three electrolyte solutions used in the present work are shown in Table 1. One can observe that the shift of $\gamma$ caused by the applied potential affects the $D_{\mathrm{s}}$ 


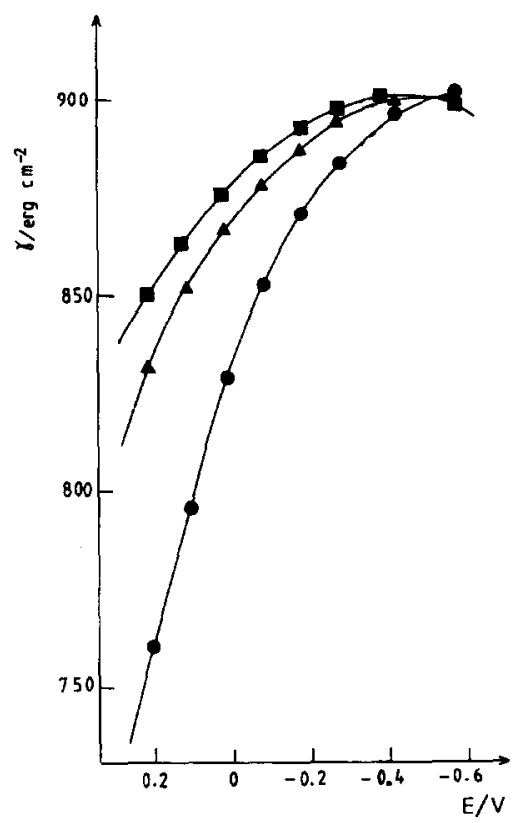

Fig. 3. Plot of $\gamma$ vs. $E$ for a smooth polycrystalline Au electrode in $0.05 \mathrm{M} \mathrm{NaF}(\boldsymbol{\nabla}), 0.05 \mathrm{M} \mathrm{K}_{2} \mathrm{SO}_{4}(\Delta)$ and $0.05 \mathrm{M} \mathrm{KCl}(\bullet)$.

TABLE 1

Values of $\Delta y, D_{\mathrm{s}}$ and $D_{\mathrm{sc}}$ obtained for polycrystalline $\mathrm{Au}$ in different electrolyte aqueous solutions and applied potential conditions at $25^{\circ} \mathrm{C}$.

\begin{tabular}{lccc}
\hline$E / V$ & $\Delta y / \mathrm{erg} \mathrm{cm}^{-2}$ & $D_{\mathrm{s}} \times 10^{14} / \mathrm{cm}^{2} \mathrm{~s}^{-1}$ & $D_{\mathrm{sc}} \times 10^{14} / \mathrm{cm}^{2} \mathrm{~s}^{-1}$ \\
\hline $0.05 \mathrm{M} \mathrm{NaF}$ & & & \\
-0.6 & 2.4 & 4.4 & 4.4 \\
-0.45 & 0.0 & 8.1 & 8.1 \\
-0.30 & 2.6 & 5.6 & 5.6 \\
0.0 & 24.5 & 8.5 & 8.7 \\
0.20 & 53.1 & 31 & 33 \\
$0.05 \mathrm{M} \mathrm{K}_{2} \mathrm{SO}_{4}$ & & & \\
-0.6 & 1.0 & 8.1 & 8.1 \\
-0.45 & 1.0 & 13 & 13 \\
-0.30 & 6.4 & 23 & 23 \\
0.0 & 34.0 & 28 & 29 \\
0.20 & 68.0 & 44 & 47 \\
$0.05 \mathrm{M} \mathrm{KCl}$ & & & \\
-0.6 & 0.5 & 63 & 63 \\
-0.45 & 5.0 & 92 & 92 \\
-0.30 & 17.7 & 110 & 110 \\
0.0 & 75.0 & 220 & 240 \\
0.2 & 140 & 350 & 410 \\
\hline
\end{tabular}




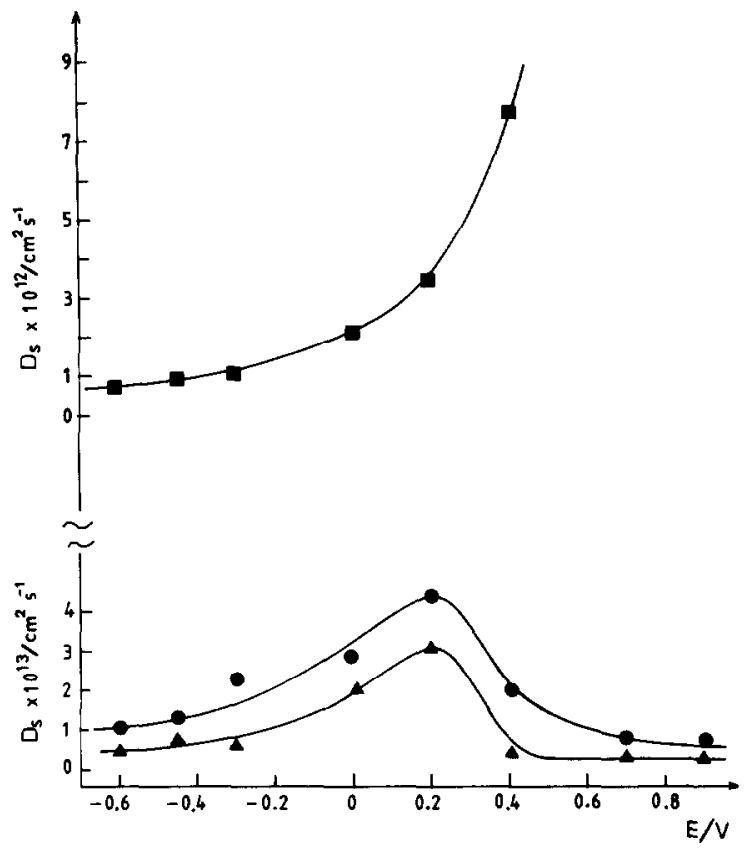

Fig. 4. Plots of $D_{\mathrm{s}}$ vs. $E_{\mathrm{g}}$ in different electrolyte solutions: $\triangle, 0.05 \mathrm{M} \mathrm{NaF} ; \bullet, 0.05 \mathrm{M} \mathrm{K}_{2} \mathrm{SO}_{4} ; \boldsymbol{\square}, 0.05$ $\mathrm{M} \mathrm{KCl}$.

values by less than $10 \%$, as calculated with $\gamma=900 \mathrm{erg} \mathrm{cm}^{-2}$, even at the most positive potentials. It should be noted that values of $\gamma$ in the range 900-1480 erg $\mathrm{cm}^{-2}$ are reported in the literature for polycrystalline $\mathrm{Au}$ [15]. The use of the highest $\gamma$ value would decrease all the reported values of $D_{\mathrm{s}}$ by a factor of 1.5 . Nevertheless, at present, there is no conclusive argument to decide which is the most reliable value of $\gamma$ to be used in the calculations.

This fact introduces a certain limitation to the method of obtaining absolute $D_{\mathrm{s}}$ values, although the comparison of $D_{\mathrm{s}}$ values for different electrolyte solutions and applied potentials remains valid. Furthermore, concerning the question of whether the effective surface tension of small crystallites is similar to the bulk value, it should be mentioned that some $\gamma$ values higher than the bulk value have been measured for small metal crystallites, using the Gibbs-Kelvin equation [16]. These results, however, were probably due to a systematic error in the measurements [16]. Also, small Ag crystallites in photographic emulsions exhibit normal $\gamma$ values with respect to the bulk $\mathrm{Ag}$ [16].

The $D_{\mathrm{s}}$ vs. $E_{\mathrm{g}}$ plots for the different aqueous solutions are shown in Fig. 4. In $0.05 \mathrm{M} \mathrm{NaF}$, the value of $D_{\mathrm{s}}$ increases from $5 \times 10^{-14} \mathrm{~cm}^{2} \mathrm{~s}^{-1}$ at $E_{\mathrm{g}}=-0.6 \mathrm{~V}$ to a maximum value $D_{\mathrm{s}}=2.5 \times 10^{-13} \mathrm{~cm}^{2} \mathrm{~s}^{-1}$ at $E_{\mathrm{g}} \approx 0.2 \mathrm{~V}$. Likewise, for $E_{\mathrm{g}}>0.2$ $\mathrm{V}, D_{\mathrm{s}}$ decreases to a value similar to that obtained at $E_{\mathrm{g}}=-0.6 \mathrm{~V}$. In $0.05 \mathrm{M}$ $\mathrm{K}_{2} \mathrm{SO}_{4}$, the same trend can be observed, although, in this case, the $D_{\mathrm{s}}$ values become slightly higher than those obtained in $\mathrm{NaF}$ aqueous solution. Thus, $D_{\mathrm{s}}$ 
increases from $E_{\mathrm{g}}=-0.60 \mathrm{~V}$ to attain a maximum value $D_{\mathrm{s}}=4.5 \times 10^{-13} \mathrm{~cm}^{2} \mathrm{~s}^{-1}$ at $E_{\mathrm{g}}=0.2 \mathrm{~V}$ and, finally, decreases to a value close to that observed at $E_{\mathrm{g}}=-0.6$ V. Otherwise, in $0.05 \mathrm{M} \mathrm{KCl}, D_{\mathrm{s}}$ increases as $E_{\mathrm{g}}$ increases, so that $D_{\mathrm{s}}=8 \times 10^{-12}$ $\mathrm{cm}^{2} \mathrm{~s}^{-1}$ at $E_{\mathrm{g}}=0.4 \mathrm{~V}$. As already mentioned, in $0.05 \mathrm{M} \mathrm{KCl}$ at potentials greater than $0.4 \mathrm{~V}$, the proper $\mathrm{Au}$ electrodissolution reaction takes place. This fact restricts our roughness relaxation measurements up to $E_{\mathrm{g}} \leq 0.4 \mathrm{~V}$.

The present results indicate that, at a constant potential, the mobility of $\mathrm{Au}$ surface atoms increases with the solution composition, according to the order $\mathrm{NaF}<\mathrm{K}_{2} \mathrm{SO}_{4}<\mathrm{KCl}$. This sequence agrees with the specific adsorption ability of anions on $\mathrm{Au}$ [17]. Therefore, the effect of the applied potential on $D_{\mathrm{s}}$ can be explained through the potential dependence of anion specific adsorption.

In $0.05 \mathrm{M} \mathrm{KCl}$, the surface mobility of $\mathrm{Au}$ is enhanced, as the applied potential is shifted positively and the $\mathrm{Cl}^{-}$ion concentration in solution is increased [3]. In this case, it appears that the strong interaction of $\mathrm{Cl}^{-}$ions with Au surface atoms leads to a faster displacement of the metal atoms. This conclusion agrees with in situ STM data of Au single crystals in acid solutions containing $\mathrm{Cl}^{-}$ions [11,18], which indicates an increase in the step motion induced by $\mathrm{Cl}^{-}$adsorption. However, it was also observed that a correlation exists between the surface mobility of metal atoms and the melting temperature $T_{\mathrm{m}}$ of the metal [1]. The formation of surface metal compounds with melting temperatures $T_{\mathrm{ms}}$ lower than $T_{\mathrm{m}}$ induces surface mobility. This assumption is based on the empirical relationships [1]

$D_{\mathrm{s}} \propto \exp \left(-K T_{\mathrm{m}}\right)$

$D_{\mathrm{s}} \propto \exp \left(-K T_{\mathrm{ms}}\right)$

where $K$ is a proportionality constant. Accordingly, for $\mathrm{AuCl}_{3}$, a possible surface compound at the $\mathrm{Au}-\mathrm{Cl}$ aqueous solution interface at sufficiently high positive potentials, $T_{\mathrm{ms}}=256^{\circ} \mathrm{C}$ [19], i.e. a value which is much lower than $T_{\mathrm{m}}=1063^{\circ} \mathrm{C}$ for Au. Considering that, for Au surface atoms in vacuo, $D_{\mathrm{s}} \approx 10^{-15} \mathrm{~cm}^{2} \mathrm{~s}^{-1}$, eqns. (4) and (5) predict that at the $\mathrm{Au} / \mathrm{AuCl}_{3} / \mathrm{Cl}^{-}$interface $D_{\mathrm{s}} \approx 10^{-11} \mathrm{~cm}^{2} \mathrm{~s}^{-1}$, i.e. a value which is in good agreement with that obtained from the $D_{\mathrm{s}}$ vs. $E_{\mathrm{g}}$ plot in $0.05 \mathrm{M} \mathrm{KCl}$ (Fig. 4) at high positive potentials. Hence, the observed increase in the surface mobility of $\mathrm{Au}$ in $0.05 \mathrm{M} \mathrm{KCl}$ can be reasonably justified throughout the formation of the $\mathrm{AuCl}_{3}$ surface compound.

In $0.05 \mathrm{M} \mathrm{NaF}$ and $0.05 \mathrm{M} \mathrm{K}_{2} \mathrm{SO}_{4}$, the surface mobility of Au increases as $E_{\mathrm{g}}$ is increased. This effect can also be assigned to anion adsorption. However, in this case, $D_{\mathrm{s}}$ reaches a maximum value at $0.2 \mathrm{~V}$, i.e. a potential where the electroformation of $\mathrm{AuOH}$ species begins [20], and decreases markedly for $E_{\mathrm{g}}>0.2 \mathrm{~V}$. These results indicate that, at potentials greater than $0.2 \mathrm{~V}$, both $\mathrm{SO}_{4}^{2-}$ ions, which are adsorbed on $\mathrm{Au}$, and $\mathrm{F}^{-}$ions, which are very weakly adsorbed on $\mathrm{Au}$, participate in the following displacement reactions:

$$
\begin{aligned}
& \{\mathrm{Au}\}\left(\mathrm{SO}_{4}^{-2}\right)+\mathrm{H}_{2} \mathrm{O} \rightarrow\{\mathrm{Au}\} \mathrm{OH}+\mathrm{SO}_{4}^{2-}+\mathrm{H}^{+}+\mathrm{e}^{-} \\
& \{\mathrm{Au}\}\left(\mathrm{F}^{-}\right)+\mathrm{H}_{2} \mathrm{O} \rightarrow\{\mathrm{Au}\} \mathrm{OH}+\mathrm{F}^{-}+\mathrm{H}^{+}+\mathrm{e}^{-}
\end{aligned}
$$


where the braces denote adsorption sites at the Au surface and the parentheses denote adsorbed species. According to the present results, the effect of $\mathrm{SO}_{4}^{-2}$ ions on the surface mobility of $\mathrm{Au}$ atoms is greater than that of $\mathrm{F}^{-}$ions.

This fact also can be understood through the interaction between the $\mathrm{SO}_{4}^{-2}$ ions and $\mathrm{Au}$ surface atoms. The effect of the specific adsorption of $\mathrm{SO}_{4}^{2-}$ ions on $\mathrm{Au}$ in acid solution has been observed [21] over the same potential range, where the value of $D_{\mathrm{s}}$ increases with potential. The adsorption of $\mathrm{SO}_{4}^{2-}$ on low index, single-crystal planes produces an overlay lattice of anions with holes, in which $\mathrm{OH}$ species can be adsorbed [21]. The decrease in the mobility of the Au surface atoms induced by $\mathrm{AuOH}$ electroformation is seemingly in contrast to recent in situ atomic force microscopy observations for the Au surface in $0.5 \mathrm{M} \mathrm{H}_{2} \mathrm{SO}_{4}$ [22]. However, in this case, the annealing of the surface Au was observed at potentials where the Au oxide electroformation takes place, changing the properties of the surface. Therefore, no reliable quantitative comparison of surface mobility data is possible.

The value of $D_{\mathrm{s}}=8 \times 10^{-14} \mathrm{~cm}^{2} \mathrm{~s}^{-1}$ for polycrystalline Au in solutions containing $\mathrm{F}^{-}$ions at $E_{\mathrm{g}} \approx 0.0 \mathrm{~V}$ is slightly higher than $D_{\mathrm{s}}=2 \times 10^{-15} \mathrm{~cm}^{2} \mathrm{~s}^{-1}$, as given in ref. 4 for $\mathrm{Au}(111)$ in $0.1 \mathrm{M} \mathrm{HClO}_{4}$ at a similar potential, using in situ STM. It should be noted that, although both $D_{\mathrm{s}}$ values are obtained in solutions containing weakly adsorbable anions, they refer to different $\mathrm{pH}$ values and crystallographic surface conditions.

Finally, it should be noted that, even at the most negative potentials, an effect of the solution composition is still observable. In this case, this effect cannot be explained in terms of anion adsorption, but should be assigned to the proper electrolyte structure at the electrochemical interface. The structure of the solution in contact with the Au surface atoms depends on the nature of the anions in the solution [23] and, in particular, on the size of the anions and their capability for hydrogen bonding interaction with water. The effect of the solution structure on the electrochemical characteristics of the metal-solution interface should be reflected over the entire potential range covered by the present work.

\section{CONCLUSIONS}

Previous results provide valuable information about the kinetics and mechanism of roughness decay at metal-solution interfaces and the effect of anion adsorption on the decay process. They offer basic information for predicting the stability and duration of rough metal electrodes of interest in electrocatalytic reactions.

However, data reported in this work become particularly interesting for a comprehensive approach to metal corrosion processes, such as stress corrosion cracking. As already mentioned [19], the lack of $D_{\mathrm{s}}$ values for electrochemical systems and their dependence on the applied potential and electrolyte composition are the relevant problems to test stress corrosion cracking models. The present results show that, even in dilute aqueous solutions containing $\mathrm{Cl}^{-}$ions, the surface Au atom mobility at high positive potentials becomes about three orders of magnitude greater than that resulting in aqueous solutions containing weakly 
adsorbed anions or organic adsorbates [3]. For the latter solutions, the $D_{\mathrm{s}}$ values are similar to those reported for Au surfaces in vacuo [1]. The increased surface mobility of $\mathrm{Au}$ in solutions containing $\mathrm{Cl}^{-}$ions can explain the susceptibility to corrosion of $\mathrm{Au}$ alloys in $\mathrm{FeCl}_{3}$ [24]. Otherwise, at potential values where the $\mathrm{Au}$ oxide layer formation commences, the Au atom surface mobility induced by weakly adsorbed anions is considerably diminished. All these facts agree with the predictions of the surface diffusion theory of stress corrosion cracking [19], concerning the protective properties of oxide and organic inhibitors, and the beneficial role of $\mathrm{Cl}^{-}$anions and the applied potential on this type of corrosion.

\section{ACKNOWLEDGMENTS}

Financial support was obtained through Projects PS88-0014 (DGICYT-Spain). RCS and AJA thank CONICET (Argentina) and the Universidad Autónoma de Madrid for their participation in this research project.

\section{REFERENCES}

1 H.P. Bonzel, in J.M. Blakely (Ed.), Surface Physics of Materials, Academic Press, New York, 1975, p. 280.

2 C. Alonso, R.C. Salvarezza, J.M. Vara, A.J. Arvia, L. Vázquez, A. Bartolomé and A.M. Baró, J. Electrochem. Soc., 137 (1990) 2161.

3 C. Alonso, R.C. Salvarezza, J.M. Vara and A.J. Arvia, Electrochim. Acta, 35 (1990) 1331.

4 D. Trevor and C.E.D. Chidsey, J. Vac. Sci. Technol. B, 9 (1991) 964.

5 C.F. Quate, in R.J. Behm, N. Garcia and H. Rohrer (Eds.), Scanning Tunneling Microscopy and Related Methods, NATO ASI Ser., Appl. Sci., 184 (1989) 281.

6 X. Gao, A. Hamelin and M.J. Weaver, Phys. Rev. Lett., 67 (1991) 618.

7 X. Gao, A. Hamelin and M.J. Weaver, Phys. Rev. B., 44 (1991) 10983.

8 A. Hamelin, X. Gao and M.J. Weaver, J. Electroanal. Chem., 323 (1991) 361.

9 A.C. Chialvo, W.E. Triaca and A.J. Arvia, J. Electroanal. Chem., 146 (1983) 93.

10 L. Vázquez, A. Bartolomé, A.M. Baró, C. Alonso, R.C. Salvarezza and A.J. Arvia, Surf. Sci, 215 (1989) 171.

11 D.J. Trevor, C.E.D. Chidsey and D.N. Loiacono, Phys. Rev. Lett., 62 (1988) 1384.

12 J. Herrera Gallego, C.E. Castellano, A.J. Calandra and A.J. Arvia, J. Electroanal. Chem., 66 (1975) 207.

13 G.M. Schmid and M.E. Curley-Fiorino, in A.J. Bard (Ed.), The Encyclopedia of Electrochemistry of the Elements, Vol. IV, Marcel Dekker, New York, 1975, p. 87, and references cited therein.

14 D.C. Grahame, E.M. Coffin, J.P. Cumming and M.A. Poth, J. Am. Chem. Soc., 74 (1952) 1207.

15 E.D. Hondros and D. Gladman, Surf. Sci., 9 (1986) 471.

16 G. Hill, A. Kaveh Pour and B. Scharifker, Electrochim. Acta, 28 (1983) 891.

17 C. Hinnen, C. Nguyen Van Huong, D. Rousseau and J.P. Dalbera, J. Electroanal. Chem., 95 (1979) 131.

18 J. Wiechers, T. Twomey, D. Kolb and R.J. Behm, J. Electroanal. Chem., 167 (1988) 237.

19 J.R. Galvele, Corros. Sci., 27 (1987) 1.

20 G. Horanyi, E.M. Rizmayer and P. Joo, J. Electroanal. Chem., 152 (1983) 211.

21 H. Angerstein-Kozlowska, B.E. Conway, A. Hamelin and L. Stoicoviciu, Electrochim. Acta, 31 (1986) 1051.

22 S. Manne, J. Massie, V.B. Elings, P.K. Hansma and A.A. Gewirth, J. Vac. Sci. Technol. B, 9 (1991) 950.

23 M.I. Florit, M.M. Martins and A.J. Arvia, J. Electroanal. Chem., 151 (1983) 209.

24 A.C.F. Cocks and M.F. Ashby, Prog. Mater. Sci., 27 (1982) 189. 